\title{
Cyclic homoconjugation in neutral organic molecules
}

\author{
Lawrence T. Scott \\ Department of Chemistry and Center for Advanced Study \\ College of Arts and Science, University of Nevada, Reno, Nevada 89557 USA
}

\begin{abstract}
Although commonly discounted as unimportant, cyclic homoconjugation in neutral organic molecules is actually quite widespread and can often confer unusual properties on the molecules in which it occurs. Several new aspects of this subject are illustrated with compounds synthesized in the author's laboratory.
\end{abstract}

\section{INTRODUCTION}

Electron delocalization over multi-atomic distances in organic molecules, though generally associated with conjugated $\pi$ systems, can be sustained to a limited degree even in homoconjugated $\pi$ systems wherein a saturated $\mathrm{CH}_{2}$ group interrupts the continuous chain of overlapping $p$ orbitals (ref. 1). In light of this fact, it is only natural that the intense research on cyclic conjugation and aromaticity which has characterized the past quarter century should broaden to include studies on cyclic homoconjugation as well.

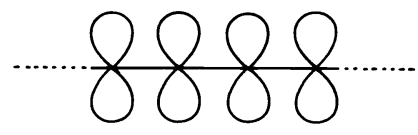

CONJUGATION

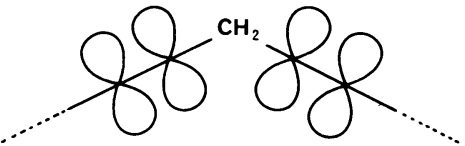

HOMOCONJUGATION

A great deal is already known about the requirements for cyclic homoconjugation and the consequences thereof. Cyclic homoconjugation involving $4 \mathrm{~N}+2$ electrons, for example, has been found to endow a variety of carbocations with aromatic properties (ref. 1-3). Among these homoaromatic ions, the homotropylium ion occupies a position comparable in prominence to that held by benzene within the family of aromatic molecules (ref. 4). Bis-homo- and even tris-homoaromatic carbocations have also been identified; however, homoaromatic species with more than three interruptions in the cycle of conjugation have never been found (ref. $1-3)$.

In neutral organic molecules, cyclic homoconjugation can also have significant electronic consequences, although it ordinarily does not impart aromatic character (ref. 3,5$)$. Aromaticity, of course, is not a necessary consequence of cyclic conjugation or homoconjugation, so its absence should not be mistaken for evidence against electron delocalization. Few would defend norbornadiene, 1 , as an aromatic species, yet photoelectron spectroscopy (PES) clearly reveals that the two $\pi$ orbitals interact quite strongly in this molecule (ref. 6). The lifting of orbital degeneracies through cyclic homoconjugation has likewise been detected by PES for hydrocarbons 2-5 (ref. 7). Cycloheptatriene, 6, gives a

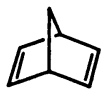

1

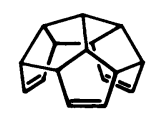

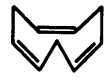

2

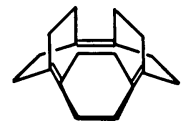

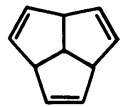

3 


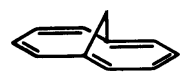

7

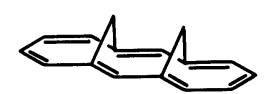

8

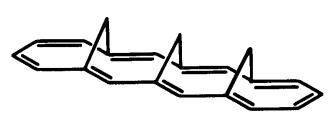

9

diamagnetic susceptibility exaltation which is nearly 608 of that of benzene (ref. 8). The absorption, polarized fluorescence, and magnetic circular dichroism (MCD) spectra of Vogel's bridged annulenes 7-9 can be explained only by recognition of the strong homoconjugative transannular interactions in these molecules (ref. 9). Thus, cyclic homoconjugation in neutral organic molecules is a very real phenomenon, and this paper will deal with some intriguing new aspects of the subject. Scant attention will be paid to whether or not the term "aromatic" applies to the compounds described. I share with the generations of chemists who have come before me a desire to understand, to explain, and ultimately to predict the observable properties of organic compounds from a knowledge of their molecular structure.

Homoconjugated polyenes $\underline{1-9}$ can be divided into two distinct classes. The first class consists of molecules in which a conjugated monocyclic $\pi$ system has been interrupted by one or more points of homoconjugation. Molecules of this class, e.g., 1-6, exhibit properties intermediate between those of acyclic and monocyclic polyenes. The second class consists of molecules in which a conjugated monocyclic $\pi$ system has been perturbed by one or more points of added transannular homoconjugation. Molecules of this class, e.g., 7-9, exhibit properties intermediate between those of monocyclic and polycyclic polyenes. ${ }^{-}$Figure 1 illustrates the distinction between these two types of cyclic homoconjugation with the simplest case in each class. Still other classes must eventually be defined in order to categorize compounds such as the "hairpin polyenes" (ref. 10); however, the two classes depicted in Fig. 1 will suffice for purposes of discussing the molecules described below.

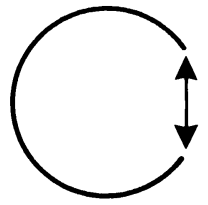

Conjugated Monocyclic $\pi$ System Interrupted by Homoconjugation (multiple interruptions possible)

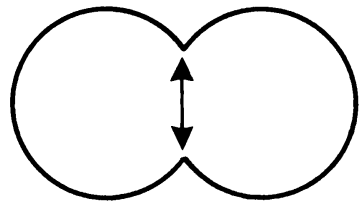

Conjugated Monocyclic $\pi$ System Perturbed by Additional Homoconjugation (multiple perturbations possible)

Fig. 1. Two classes of cyclic homoconjugation.

\section{IMPOSITION OF NONALTERNANT CHARACTER OF AN ALTERNANT HYDROCARBON $\pi$ SYSTEM THROUGH CYCLIC HOMOCONJUGATION}

At the outset it should be recalled that all hydrocarbon $\pi$ systems can be identified as either alternant or nonalternant according to the "starring" procedure of Coulson (ref. 11). Azulene, 10, for example, because it contains two adjacent atoms of like parity (see *s in 10), belongs to the family of nonalternant hydrocarbons. Homoazulene, 11, on the other hand, formally belongs to the family of alternant hydrocarbons, since it contains no atoms of like parity adjacent to one another (ignoring homoconjugation, see *s in 11). Despite this formal distinction, however, the evidence presented below reveals that the electronic properties of homoazulene resemble those of azulene more than they do those of an alternant hydrocarbon.

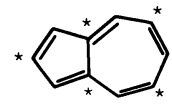

10

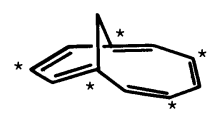

11

Many of the peculiar properties of azulene can be traced to the presence of the lone transannular bond that makes this molecule nonalternant (ref. 12). Among these special "nonalternant properties", the response of the UV-VIS absorption spectrum of azulene to the introduction of substituents on the chromophore is particularly striking. In general, benzenoid aromatics and other alternant hydrocarbons obey Woodward's familiar rules, i.e., 
ca $+5 \mathrm{~nm}$ shift in the long-wavelength absorption maximum for each alkyl substituent (ref. $\overline{13})$. Azulene, however, does not conform. A single alkyl substituent can shift the visible absorption maximum of azulene by as much as $+29 \mathrm{~nm}$ toward longer wavelength or by as much as $-14 \mathrm{~nm}$ toward shorter wavelength, depending on the site of attachment. This unusual behavior has required the development of a totally different set of empirical rules, now known as Plattner's rules, to correlate the spectral properties of azulene derivatives (ref. 14). Stronger donor substituents, such as OMe, cause proportionally larger shifts of the same sign (ref. 15).

Figure 2 summarizes Plattner's rules for azulene and gives the visible absorption maximum for homoazulene and four of its OMe-substituted derivatives (ref. 15-17). One can see immediately that homoazulene exhibits spectroscopic behavior toward substitution by a donor substituent which is decidedly atypical of an alternant hydrocarbon and in this regard appears far more similar to azulene than to an alternant hydrocarbon (ref. 17). For example, depending on the point of attachment of a single OMe group to homoazulene, the absorption maximum can be shifted either toward longer wavelength (12 and 13) or toward shorter wavelength (14) and by differing amounts. When two strong donor groups are judiciously counterpoised (15), the absorption maximum moves hardly at all! These data vividly underscore the importance of cyclic homoconjugation in neutral organic molecules and provide compelling evidence for the fact that even homoconjugation between atoms of like parity can impart nonalternant character to a neutral hydrocarbon $\pi$ system.

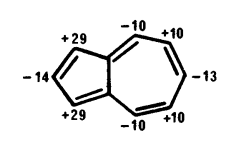

$10: 579 \mathrm{~nm}$

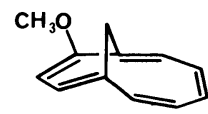

$13: 505 \mathrm{~nm}$

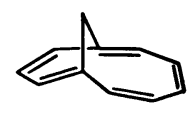

$11: 484 \mathrm{~nm}$

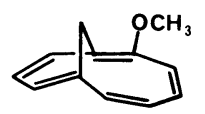

$14: 468 \mathrm{~nm}$

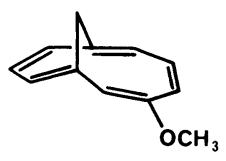

$12: 495 \mathrm{~nm}$

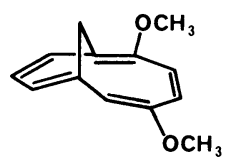

$15: 485 \mathrm{~nm}$

Fig. 2. Visible absorption spectral maxima and Plattner's rules for the effects of alkyl substituents on the azulene absorption maximum.

\section{IMPOSITION OF NONALTERNANT CHARACTER ON ALTERNANT HYDROCARBON QUINONES THROUGH CYCLIC HOMOCONJUGATION}

The ability of the homoazulene skeleton to confer nonalternant character on an otherwise alternant $\pi$ system through homoconjugation opens the door to studies beyond those on the perturbed annulene and its substituted relatives. From an historical perspective, the quinones of homoazulene seem especially worthy of study, for no family of compounds has been more closely associated with aromatic hydrocarbons through the years than has the family of quinones (ref. 18). Vogel and his coworkers have recently prepared several quinones of the alternant bridged annulenes $\underline{7}$ and $\underline{8}$ (ref. 19).

Figure 3 shows three quinones of homoazulene together with the corresponding quinones of azulene. All of these compounds except the 4,7-quinone of azulene, 18, have been synthesized recently for the first time in Reno (ref. 20,21). Quinone 18 remains unknown, but its properties have been predicted on the basis of molecular orbital calculations (ref. 22). From Fig. 3, it will be noted that these quinones of azulene absorb light at shorter wavelengths than does azulene itself. Such behavior is precisely the reverse of that which is observed for alternant systems; the quinones of benzene and naphthalene, for example, are yellow, orange, and red, whereas the parent hydrocarbons are colorless (ref. 18). This peculiarity of the azulenic compounds is well accounted for by the theoretical calculations, which take into consideration the nonalternant nature of the $\pi$ system (ref. 22). In the homoazulenic series, this same peculiarity is preserved (Fig. 3). Thus, quinones 19-21 behave more like the nonalternant quinones of azulene than like quinones of a purely alternant [10]annulene. Clearly, the nonalternant homoconjugative perturbation enforced by the homoazulene skeleton affects the electronic properties of these new quinones just as it affects the properties of the parent hydrocarbon. The nonalternant character of quinones 19-21 beautifully illustrates the fact that cyclic homoconjugation can have important consequences even in non-aromatic organic molecules. 


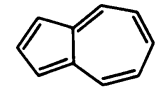

$10: 579 \mathrm{~nm}$

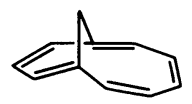

$11: 484 \mathrm{~nm}$

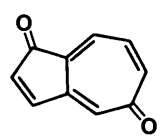

$16: 389 \mathrm{~nm}$

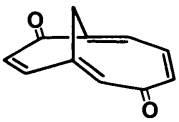

$19: 327 \mathrm{~nm}$

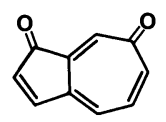

$17: 425 \mathrm{~nm}$

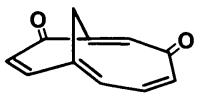

$20: 340 \mathrm{~nm}$<smiles>O=C1C=CC(=O)C2=CC=CC2=C1</smiles>

$18:(529 \mathrm{~nm})$

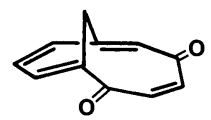

21 : $382 \mathrm{~nm}$

Fig. 3. Long wavelength maxima in the UV-VIS absorption spectra of azulene, homoazulene, and some of their quinones. All the data were obtained experimentally except that for $\underline{18}$, which was calculated.

\section{HOMOCONJUGATIVE INTERRUPTION OF A NONALTERNANT $\pi$ SYSTEM}

Homoazulene and its quinones contain a fully-conjugated perimeter $\pi$ system that takes on nonalternant character in response to an extra transannular homoconjugative perturbation (Figure 1.B). In principle, nonalternant homoconjugated $\pi$ systems of a completely different type should be accessible by introducing one or more homoconjugative interruptions into a neutral monocyclic $\pi$ system that is already nonalternant (Figure 1.A). Tropone, 22, represents a particularly attractive starting point for these studies since cyclic conjugation therein gives rise to such pronounced effects (ref. 23). The carbonyl stretching band in the IR spectrum of 22 , for example, appears at remarkably low frequency $\left(1590 \mathrm{~cm}^{-1}\right)$, and the oxygen atom is far more easily protonated than that of ordinary unsaturated ketones (ref. $23,24)$. In cyclo-octatrienone, 23, a monohomotropone, these special properties are drastically attenuated (ref. 24,25), presumably because the orbitals at the homoconjugation gap do not overlap well. By contrast, the bridged homotropone 24, synthesized recently in Reno, retains much of the special character of tropone (ref. 26 ). The carbonyl stretching band in the IR spectrum of 24 , for example, appears at $1594 \mathrm{~cm}^{-1}$, and the oxygen atom can be protonated by trifluoroacetic acid, even in dilute chloroform solution, to generate the stable bridged homotropylium ion 25. As anticipated, the trimethylene bridge in 24 enforces overlap of the orbitals flanking the gap in the $\pi$ system, thereby allowing electron delocalization around the entire cycle. This example draws attention to the importance of cyclic homoconjugation even in certain neutral nonalternant systems.<smiles>O=c1cccccc1</smiles>

22<smiles>O=C1C=CC=CC=CC1</smiles>

23

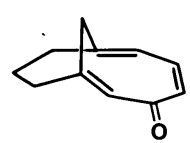

24

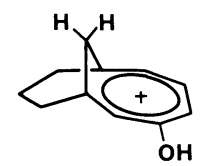

25
$\operatorname{IR}(\mathrm{C}=0) 1590 \mathrm{~cm}^{-1}$
$\operatorname{IR}(\mathrm{C}=0) 1670 \mathrm{~cm}^{-1}$
$\operatorname{IR}(\mathrm{C}=0) 1594 \mathrm{~cm}^{-1}$
$1_{\mathrm{H} \text { NMR } \Delta \delta 2.53}$

\section{MULTIPLE HOMOCONJUGATIVE INTERRUPTION OF NEUTRAL MONOCYCLIC $\pi$ SYSTEMS}

The last family of compounds to be examined reveals the importance of cyclic electron delocalization even in neutral monocyclic $\pi$ systems with multiple homoconjugative interruptions. As a calibration point, it should be remembered that three or more homoconjugative interruptions in the tropylium ion $\pi$ system effectively quench its homoaromatic properties (ref. 3 ).

Macrocyclic hydrocarbons comprised entirely of $-\mathrm{C} \equiv \mathrm{C}-$ units and $\mathrm{CH}_{2}$ groups joined together in alternation around the perimeter, e.g., 26, 27, and 28, constitute an intriguing class of molecules for which the name "pericyclynes" has been suggested, to connote the presence of
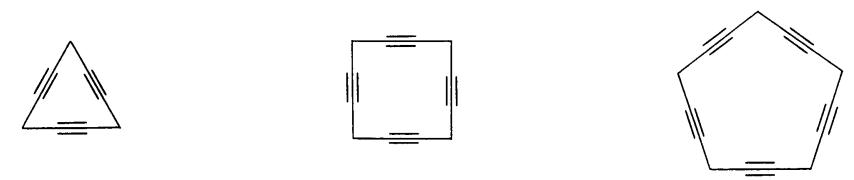
alkyne functionality on every side of the ring (ref. 27); a numeral prefix, [N], indicates both the number of corners ( $\mathrm{CH}_{2}$ groups) and the number of sides (-CEC- units) that constitute a particular pericyclyne. Such compounds display a variety of interesting properties.

Consider first the $p$ orbitals in [3]pericyclyne. These can be divided into two sets, one in-plane and one out-of-plane. All six out-of-plane p orbitals line up perfectly parallel to one another and comprise a $\pi$ system much like that in benzene, only with three homoconjugative interruptions. Orthogonal to this, the six in-plane $p$ orbitals form a cyclic array in the center of the ring (cf. 2-5). Each set contains six electrons, thus making [3]pericyclyne a double-barreled tris-homobenzene (ref. 28). In [4]pericyclyne, each set contains 8 electrons, whereas in [5]pericyclyne, two $4 \mathrm{~N}+2$ systems are again found.

Neither the [3]pericyclyne nor the [4]pericyclyne ring system is currently known; however, Sakurai and his group in Japan have reported an analog of 26 with silicon atoms at the corners (ref. 29). In Reno, the fully-methylated pericyclynes of order [5], [6], [7], and [8] (29-32) have been synthesized (ref. 27,30). These novel hydrocarbons are all highmelting, air-stable, colorless crystalline solids. The photoelectron spectra (PES) and electron transmission spectra (ETS) of 29 and 30 confirm the high degree of orbital mixing (cyclic homoconjugation) in these pericyclynes Tref. 31); PES and ETS data are not yet available for the higher family members 31 and 32 .

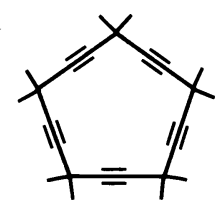

$m p 201-202^{\circ} \mathrm{C}$

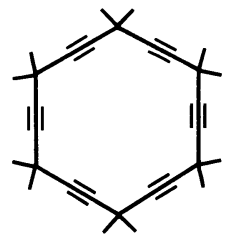

$m p 248-249^{\circ} \mathrm{C}$

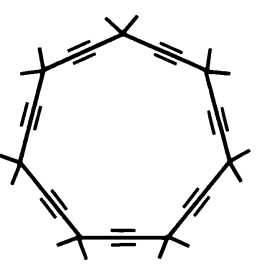

$\operatorname{mp} 170-171^{\circ} \mathrm{C}$

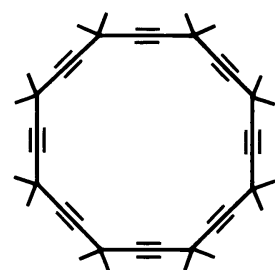

$\operatorname{mp} 184-185^{\circ} \mathrm{C}$

The PES of 29 shows one sharp $\pi$ ionization potential ( $\pi$ IP) at $9.07 \mathrm{eV}$, another sharp $\pi$ IP at $10.20 \mathrm{eV}$, and at least three more incompletely resolved strong $\pi$ IPs between these two in energy. In the absence of any electronic interaction among the acetylenic units in 29 , the molecule would have five degenerate in-plane $\pi$ bonds and five degenerate out-of-plane $\pi$ bonds. Such an arrangement would give rise to just one $\pi$ IP for the in-plane $\pi$ electrons and to one $\pi$ IP for the out-of-plane electrons, i.e., to only two $\pi$ IPs, which might or might not be distinguishable be PES. The large number of $\pi$ IPs observed, however, can be taken as evidence that cyclic homoconjugation splits these degeneracies. Ab initio molecular orbital calculations predict six distinct $\pi$ IPs for 29, but those of intermediate energy may partially overlap (ref. 31,32). The range of $\pi$ IPS $(1.13 \mathrm{eV}$ ) indicates that the orbital interactions in 29 must be quite substantial. Pericyclyne 30 gives a similar PES with the $\pi$ IPs grouped somewhat differently.

The electron affinities (EAs) of 29 and 30 , as measured by ETS in the gas phase, reveal an even stronger mixing among the unfilled orbitals, in agreement with theory (ref. 31 ). The LUMO of $29(-1.87 \mathrm{eV})$ lies more than $1.0 \mathrm{eV}$ below that of an isolated dialkyl acetylene, and the splitting between the first and second unoccupied MOs of 29 measures $1.58 \mathrm{eV}$ ! The LUMO of $30(-2.15 \mathrm{eV})$ likewise lies unusually low in energy and is separated from the second unoccupied MO by a remarkably large gap $(1.60 \mathrm{eV})$.

These studies on the pericyclynes demonstrate that cyclic homoconjugation can have important electronic consequences even in neutral monocyclic $\pi$ systems with five or six homoconjugative interruptions.

\section{CONCLUSION}

Nowhere in the foregoing discussion has it been claimed (or denied) that cyclic homoconjugation in neutral molecules can impart any special thermodynamic stability or aromatic character. That question, though an interesting one, cannot be answered by the data cited here. The primary purpose of this paper has been rather to impress upon the reader the fact that cyclic homoconjugation in neutral organic molecules is quite real and can often confer unusual properties on the molecules in which it occurs. The widespread recognition of this fact is long overdue. 


\section{ACKNOWLEDGEMENTS}

The author is indebted to his students and other collaborators whose names appear in the references cited. Financial support from the National Science Foundation, the National Institutes of Health, and Research Corporation is gratefully acknowledged.

\section{REFERENCES AND NOTES}

1. For references to the early literature on this subject, see: S. Winstein, Chem. Soc. Special Publ. 21, 5-45 (1967).

2. P. M. Warner in Topics in Nonbenzenoid Aromatic Chemistry 2, p. 283, Hirokawa Publishing Co., Tokyo (1977).

3. L. A. Paquette, Angew. Chemie, Internat. Ed. Engl. 17, 106-117 (1978).

4. R. F. Childs, Acc. Chem. Res. 17, 347-352 (1984) and references cited therein.

5. K. N. Houk, R. W. Gandour, R. W. Strozier, N. G. Rondan, and L. A. Paquette J. Am. Chem. Soc. 101, 6797-6802 (1979). L. A. Paquette, R. A. Snow, J. L. Muthard, and T. Cynkowski J. Am. Chem. Soc. 101, 6991-6996 (1979).

6. H.-D. Martin and B. Mayer Angew. Chem., Internat. Ed. Engl. 22, 283-314 (1983) and references cited therein. K. N. Houk, N. G. Rondan, M. N. Paddon-Row, C. W. Jefford, P. T. Huy, P. D. Burrow, and K. D. Jordan J. Am. Chem. Soc. 105, 5563-5569 (1983).

7. J. E. McMurry, G. J. Haley, J. R. Matz, J. C. Clardy, G. Van Duyne, R. Gleiter, W. Schafer, and D. H. White J. Am. Chem. Soc. 106, 5018-5019 (1984) and references cited therein .

8. H. J. Dauben, Jr., J. D. Wilson, and J. L. Laity J. Am. Chem. Soc. 91, 1991-1998 (1969).

9. H. J. Dewey, H. Deger, W. Frollich, B. Dick, K. A. Klingensmith, G. Hohlneicher, E. Vogel, and J. Michl J.Am. Chem. Soc. 102, 6412-6417 (1980). K. A. Klingensmith, W. Puttmann, E. Vogel, and J. Michl J. Am. Chem. Soc. 105, 3375-3380 (1983).

10. W. Frolich, H. J. Dewey, H. Deger, B. Dick, K. A. Klingensmith, W. Puttmann, E. Vogel, G. Hohlneicher, and J. Michl J. Am. Chem. Soc. 105, 6211-6220 (1983).

11. C. A. Coulson, B. O'Leary, and R. B. Mallion Hulckel Theory for Organic Chemists, Chapter 6, Academic Press, New York (1978).

12. See, for example: J. Michl and E. W. Thulstrup Tetrahedron 32, 205-209 (1976). E. Heilbronner and H. Bock The HMO-Model and its Application 2, Wiley, New York (1976).

13. E. Pretsch, J. Seibl, W. Simon, and T. Clerc Tables of Spectral Data for Structure Determination of Organic Compounds, Springer-Verlag, New York (1983).

14. Summarized by E. Heilbronner in Nonbenzenoid Aromatic Hydrocarbons, Chapter 5, D. Ginsburg, Ed., Interscience, New York (1959).

15. L. T. Scott, W. R. Brunsvold, M. A. Kirms, and I. Erden J. Am. Chem. Soc. 103, 5216-5220 (1981).

16. S. Masamune, D. W. Brooks, K. Morio, and R. L. Sobczak J. Am. Chem. Soc. 98, 8277-8279 (1976). S. Masamune and D. W. Brooks Tetrahedron Lett. 3239-3240 (1977). L. T. Scott and W. R. Brunsvold J. Am. Chem. Soc. 100, 4320-4321 (1978). L. T. Scott, W. R. Brunsvold, M. A. Kirms, and I. Erden Angew. Chem., Internat. Ed. Engl. 20, 274 (1981).

17. L. T. Scott, M. Oda, and I. Erden J. Am. Chem. Soc., submitted for publication.

18. The Chemistry of the Quinonoid Compounds, S. Patai, Ed., Wiley, New York (1974).

19. E. Vogel, personal communication.

20. L. T. Scott Pure Appl. Chem. 55, 363-368 (1983). L. T. Scott, P. Grutter, and R. E. Chamberlain, III J. Am. Chem. Soc. 106, 4852-4856 (1984). L. T. Scott and C. M. Adams J. Am. Chem. Soc. 106, 4857-4861 (1984).

21. L. T. Scott and M. Oda J. Am. Chem. Soc., submitted for publication.

22. L. T. Scott, M. D. Rozeboom, K. N. Houk, T. Fukunaga, H. J. Lindner, and K. Hafner J. Am. Chem. Soc. 102, 5169-5176 (1980).

23. D. Lloyd Non-Benzenoid Conjugated Carbocyclic Compounds, Chapter 3, Elsevier, Amsterdam (1984) and references cited therein. D. Lewis and D. Peters Facts and Theories of Aromaticity, Chapter 5, Macmillan Press, London (1975) and references cited therein.

24. R. F. Childs, D. L. Mulholland, A. Varadarajan, and S. Yeroushalmi J. Org. Chem. 48, 1431-1434 (1983).

25. A. C. Cope and B. D. Tiffany J. Am. Chem. Soc. 73, 4158-4161 (1951).

26. L. T. Scott and M. M. Hashemi Tetrahedron, in press.

27. L. T. Scott, G. J. DeCicco, J. L. Hyun, and G. Reinhardt J. Am. Chem. Soc. 105, 7760-7761 (1983).

28. The "double aromaticity" proposed by Schleyer et al. has some of these same features: J. Chandrasekhar, E. D. Jemmis, and P. V. R. Schleyer Tetrahedron Lett. 3707-3710 (1979).

29. H. Sakurai, Y. Eriyama, A. Hosomi, and Y. Nakadaira Chem. Letters 595 (1984).

30. L. T. Scott, G. J. DeCicco, J. L. Hyun, and G. Reinhardt J. Am. Chem. Soc. 107, in press.

31. K. N. Houk, L. T. Scott, N. G. Rondan, G. Reinhardt, J. L. Hyun, G. J. DeCicco, R. Weiss, M. H. M. Chen, L. S. Bass, J. Clardy, F. S. Jørgensen, V. Sarkozi, C. Petit, L. $\mathrm{Ng}$, and K. D. Jordan J. Am. Chem. Soc. 107, in press.

32. Semi-empirical calculations on pericyclynes have been reported by M. J. S. Dewar and $M$. K. Holloway J. Chem. Soc., Chem. Commun. 1188-1191 (1984). 